\title{
Mechanistic Insights into the Conversion of Bio-renewable Levoglucosanol to Dideoxysugars
}

Mingxia Zhou, ${ }^{\dagger}$ Siddarth H. Krishna, ${ }^{\ddagger}$ Mario De bruyn, ${ }^{\S}$ Bert M. Weckhuysen, ${ }^{\S}$ Larry A. Curtiss, ${ }^{\dagger}$ James A. Dumesic, ${ }^{\ddagger}$ George W. Huber, ${ }^{\ddagger}$ Rajeev S. Assary ${ }^{*}+$

${ }^{\dagger}$ Materials Science Division, Argonne National Laboratory, 9700 S Cass Ave, Lemont, Illinois 60439, United States

${ }^{\ddagger}$ Department of Chemical and Biological Engineering, University of Wisconsin-Madison, 1415 Engineering Dr, Madison, Wisconsin 53706, United States

§Faculty of Science, Debye Institute for Nanomaterials Science, Utrecht University, Universiteitsweg 99, 3584 CG Utrecht, The Netherlands.

Corresponding author: Email: assary@anl.gov (R. S. Assary), Ph: 630-252-3536

17 Pages, 15 Figures, 1 Table 
Table S1. Computed relative free energies $(\mathrm{kcal} / \mathrm{mol})$ at $373 \mathrm{~K}$ and $423 \mathrm{~K}$ of neutral molecules during LGOL conversion of DDG/DDM or DDF in water.

\begin{tabular}{|c|c|c|c|c|}
\hline Entry & Species & $a b b r$ & ${ }^{2} \Delta G^{373}$ & ${ }^{b} \Delta G^{\prime 423}$ \\
\hline 1 & threo-LGOL & TL & 0.0 & 0.0 \\
\hline 2 & erythro-LGOL & EL & 0.4 & 0.4 \\
\hline \multirow{3}{*}{3} & \multirow{3}{*}{ DDG } & $\mathrm{G}_{1}$ & 3.1 & 3.2 \\
\hline & & $\mathrm{G}_{2}$ & 4.3 & 4.4 \\
\hline & & $A_{1}$ & 10.9 & 11.1 \\
\hline 4 & $A_{1}$ gem-diol & $\mathrm{GD}_{1}$ & 7.6 & 7.7 \\
\hline \multirow{3}{*}{5} & \multirow{3}{*}{ DDM } & $M_{1}$ & 5.3 & 5.4 \\
\hline & & $\mathrm{M}_{2}$ & 2.4 & 2.4 \\
\hline & & $\mathrm{A}_{2}$ & 13.6 & 13.7 \\
\hline 6 & $A_{2}$ gem-diol & $\mathrm{GD}_{2}$ & 6.5 & 6.6 \\
\hline \multirow{5}{*}{7} & \multirow{5}{*}{ DDF } & $\mathrm{F}_{1}$ & 0.3 & 0.4 \\
\hline & & $\mathrm{F}_{2}$ & -1.3 & -1.2 \\
\hline & & $P_{1}$ & 1.8 & 1.9 \\
\hline & & $\mathrm{P}_{2}$ & 3.1 & 3.3 \\
\hline & & $\mathrm{K}_{1}$ & 3.1 & 3.2 \\
\hline 8 & $\mathrm{~K}_{1}$ gem-diol & $\mathrm{GD}_{3}$ & 5.3 & 5.4 \\
\hline
\end{tabular}




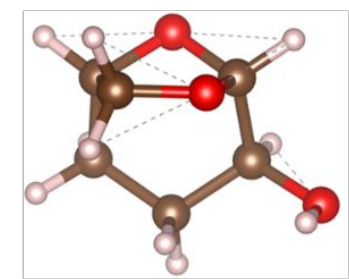

$\mathrm{TL}$

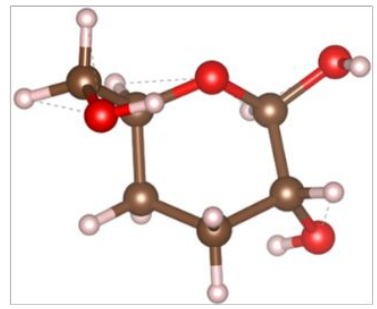

$\mathrm{G}_{2}$

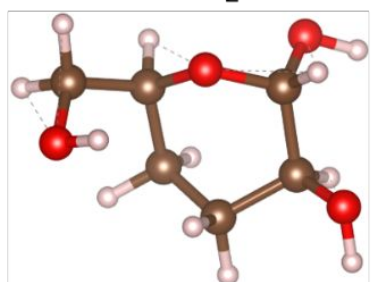

$\mathrm{M}_{1}$

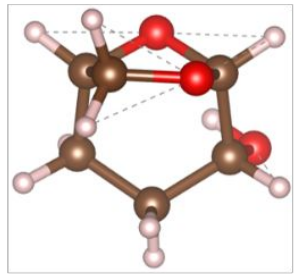

EL

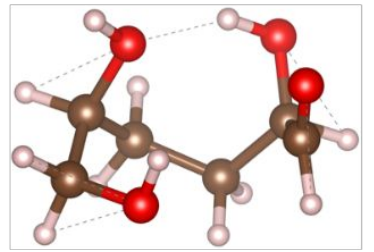

$A_{1}$

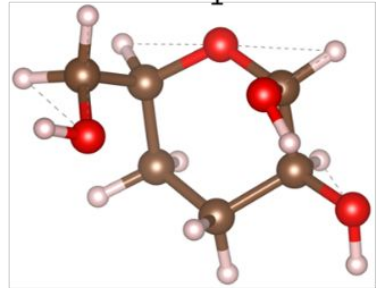

$M_{2}$

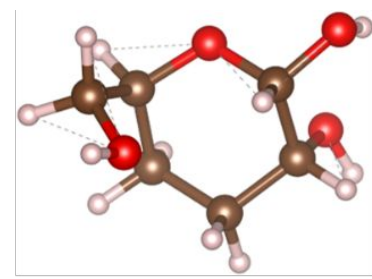

$\mathrm{G}_{1}$

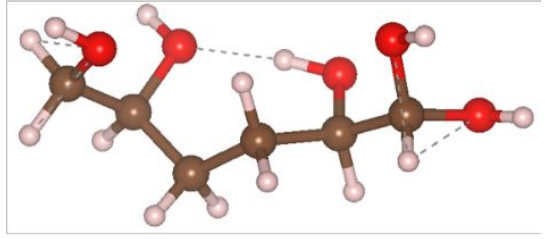

$\mathrm{GD}_{1}$

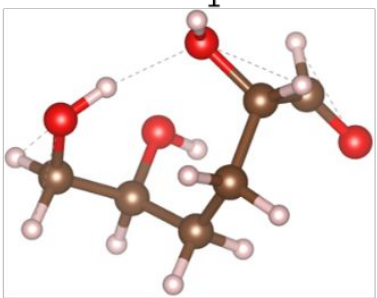

$\mathrm{A}_{2}$

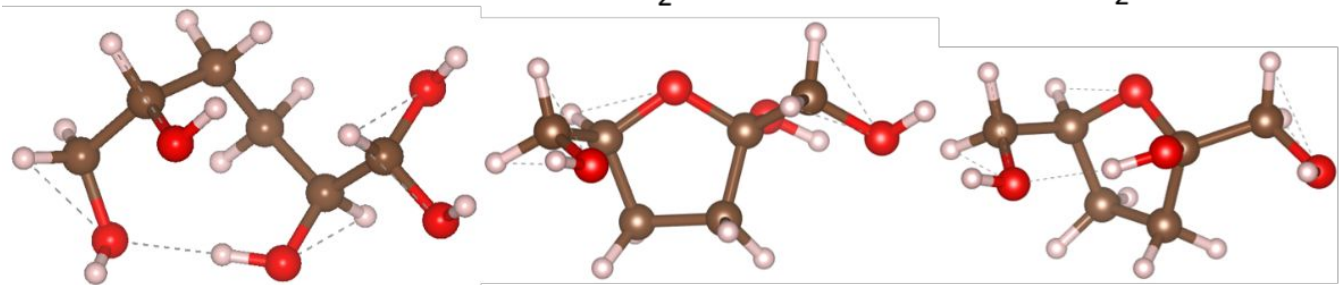

$\mathrm{GD}_{2}$

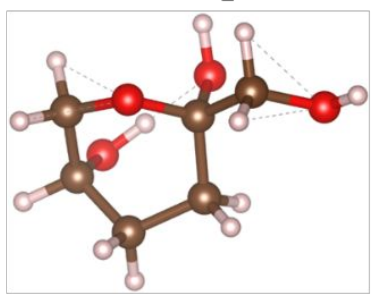

$$
P_{1}
$$
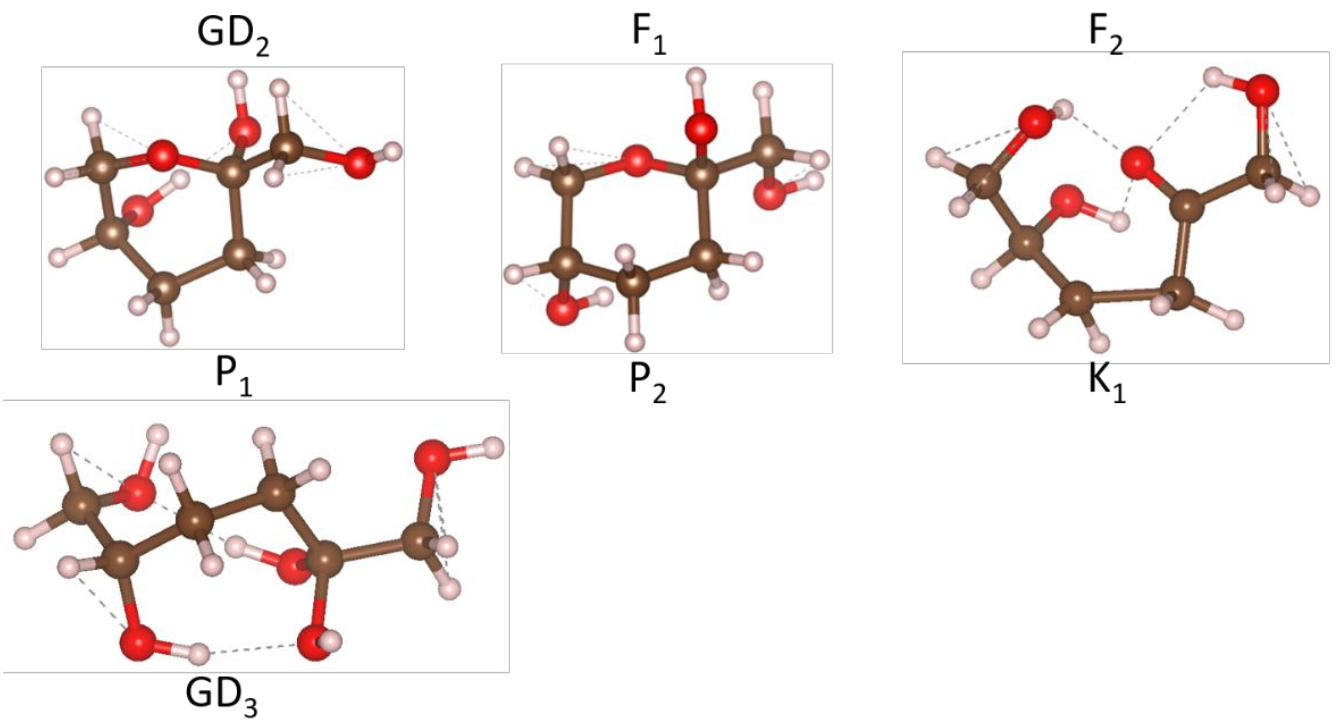

Figure S1. The optimized structures of neutral molecules during LGOL conversion in Figure 1. The dotted lines represent the hydrogen bond. 

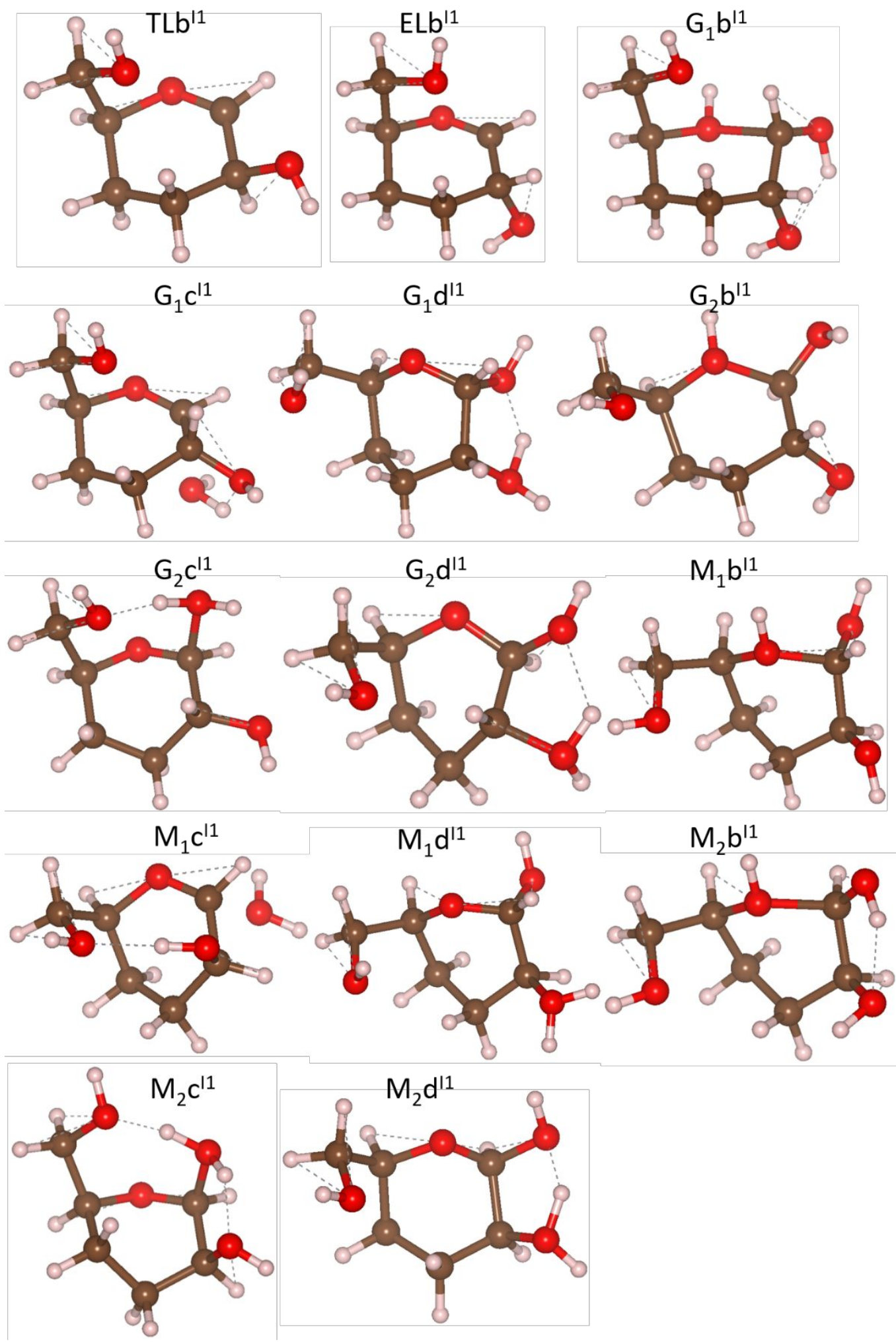

Figure $S 2$. The optimized structures of protonation of $T L, E L, G_{1}, G_{2}, M_{1}$, and $M_{2}$ in water in Figure 2. The $b, c$, and $d$ in the species name is the protonation sites and the superscript ' $l$ ' indicates the reaction intermediates. 

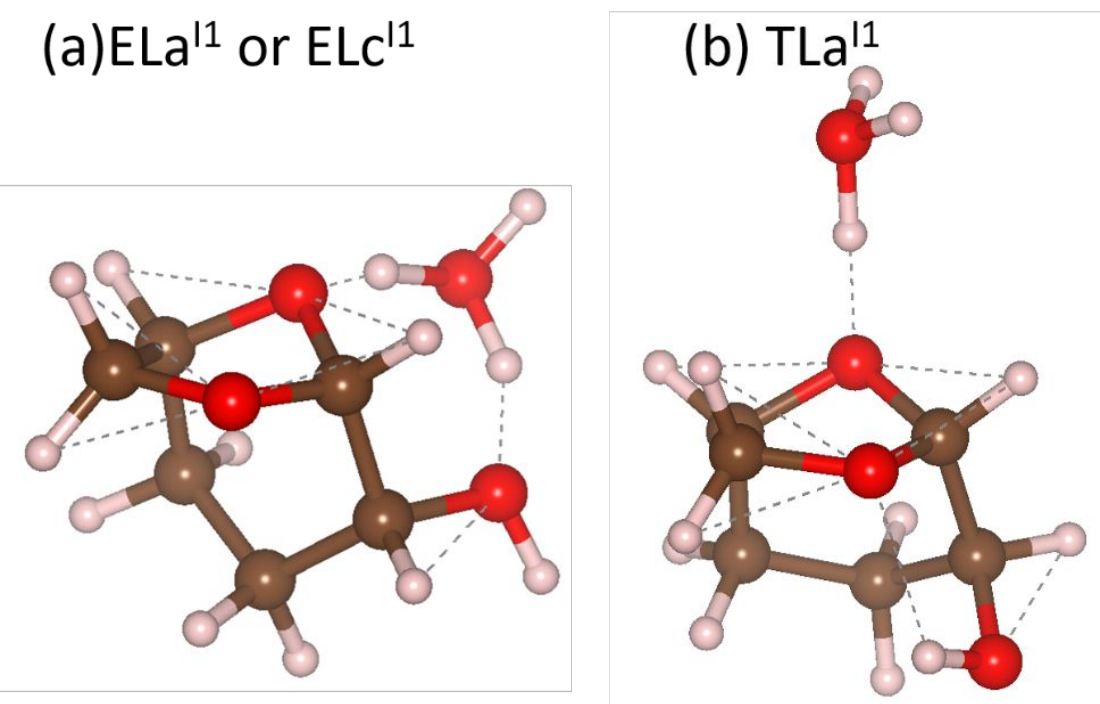

\section{(c) TLC ${ }^{11}$}

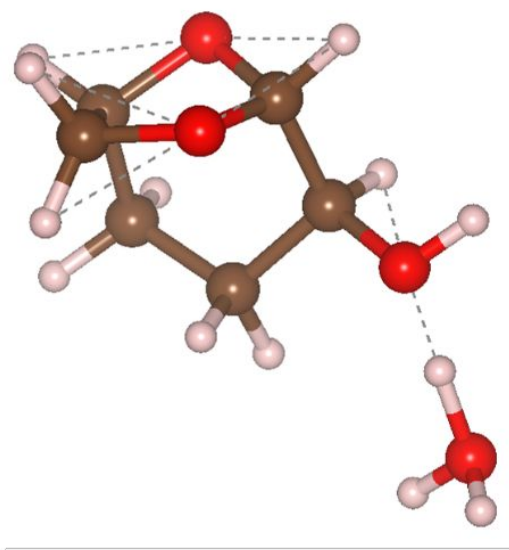

Figure S3. The optimized structure of protonation at (a) sites $a$ and $c$ of EL, (b) site $a$ of TL, and (c) site $c$ of TL. 


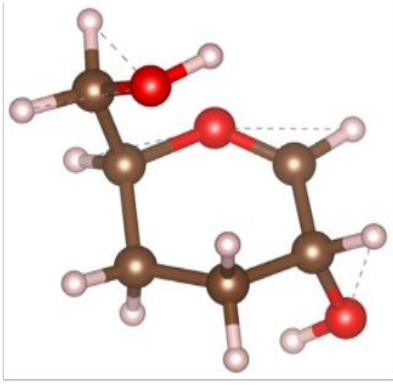

$E^{\prime \prime} b^{11}$

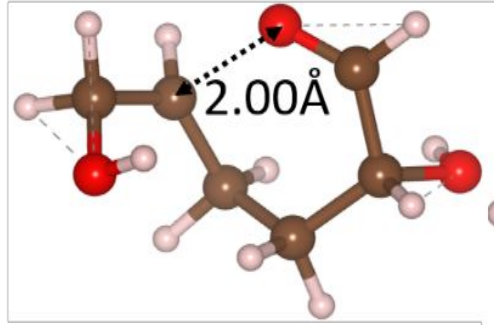

ELb $^{\mathrm{TS} 1}$

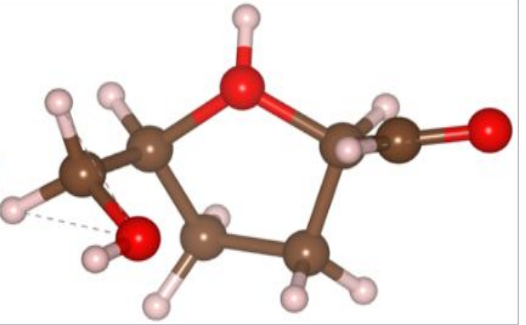

$E L^{12}$

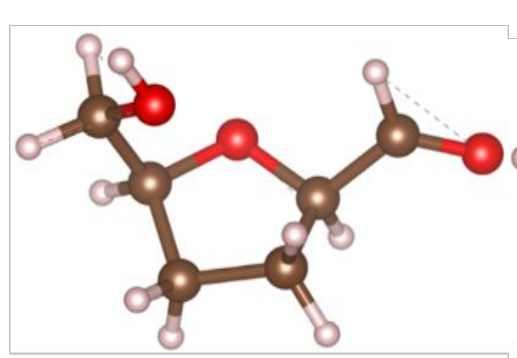

\section{$E b^{13}$}

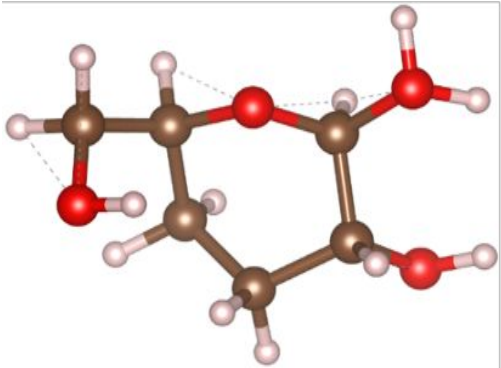

$\mathrm{ELb}^{15}$

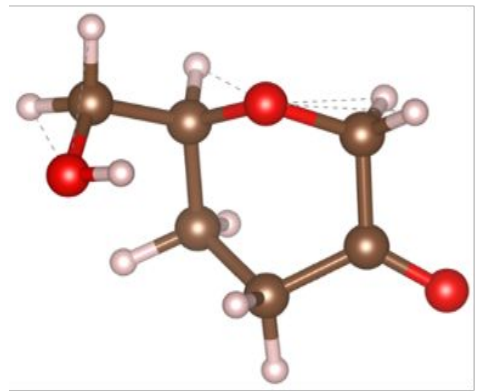

$E^{E L} b^{17}$

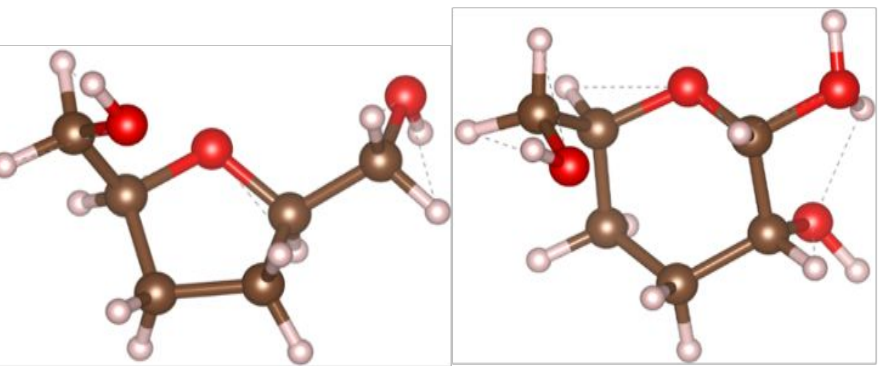

THFDM

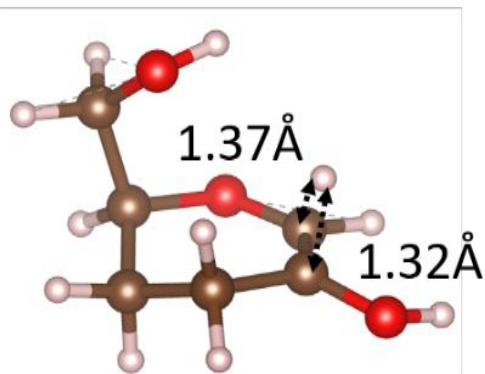

$E L^{T S 2}$

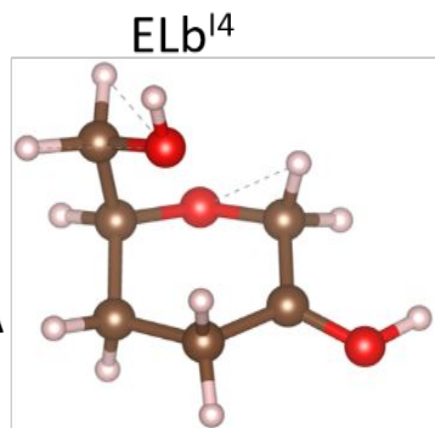

$E b^{16}$

Figure S4. The optimized structures of reaction intermediates during EL hydrolysis from Figure 3. 


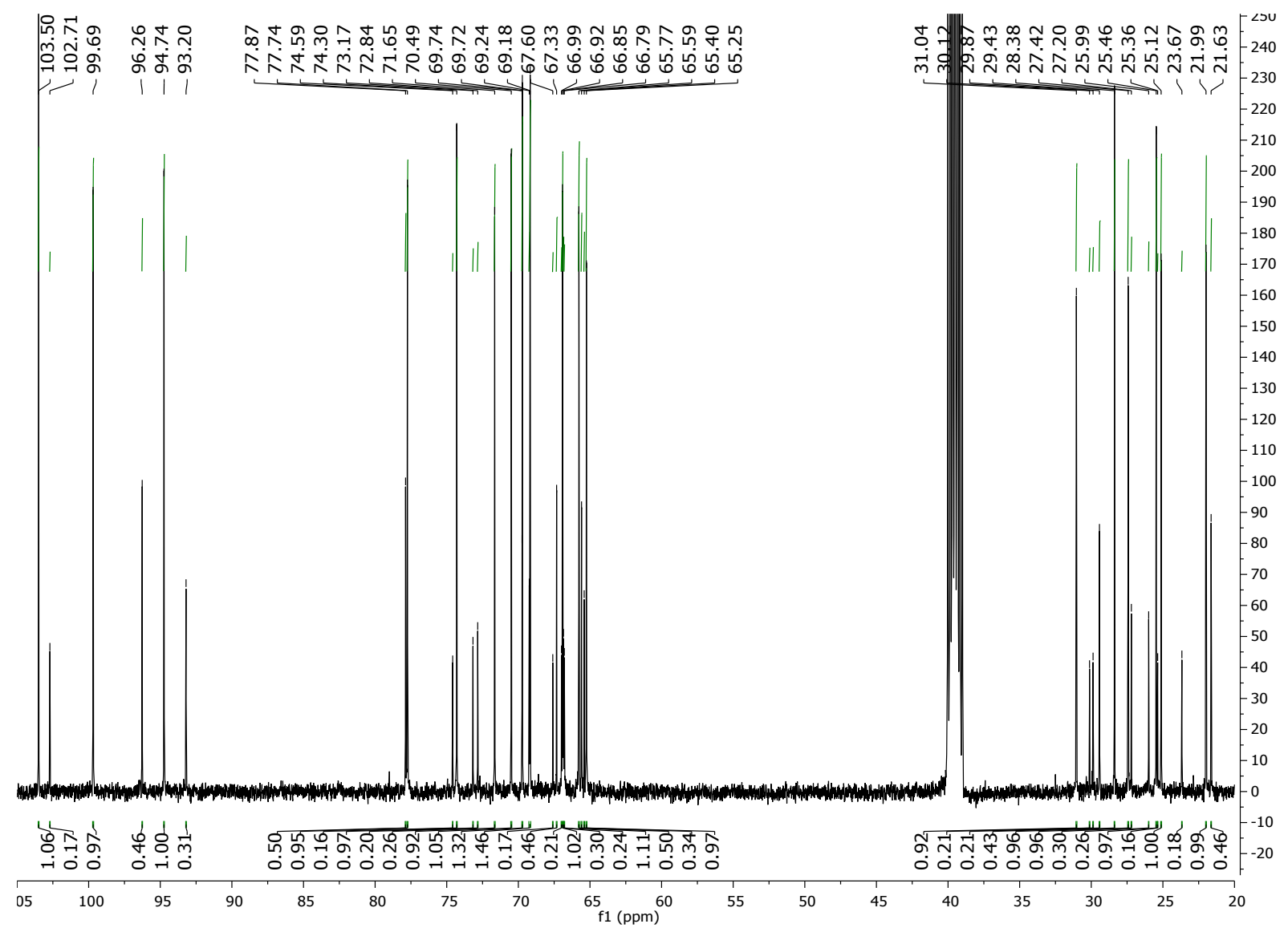

Figure S5. Typical ${ }^{13} \mathrm{C}$ NMR spectrum of an acid catalyzed LGOL hydrolysis reaction in aqueous medium. 


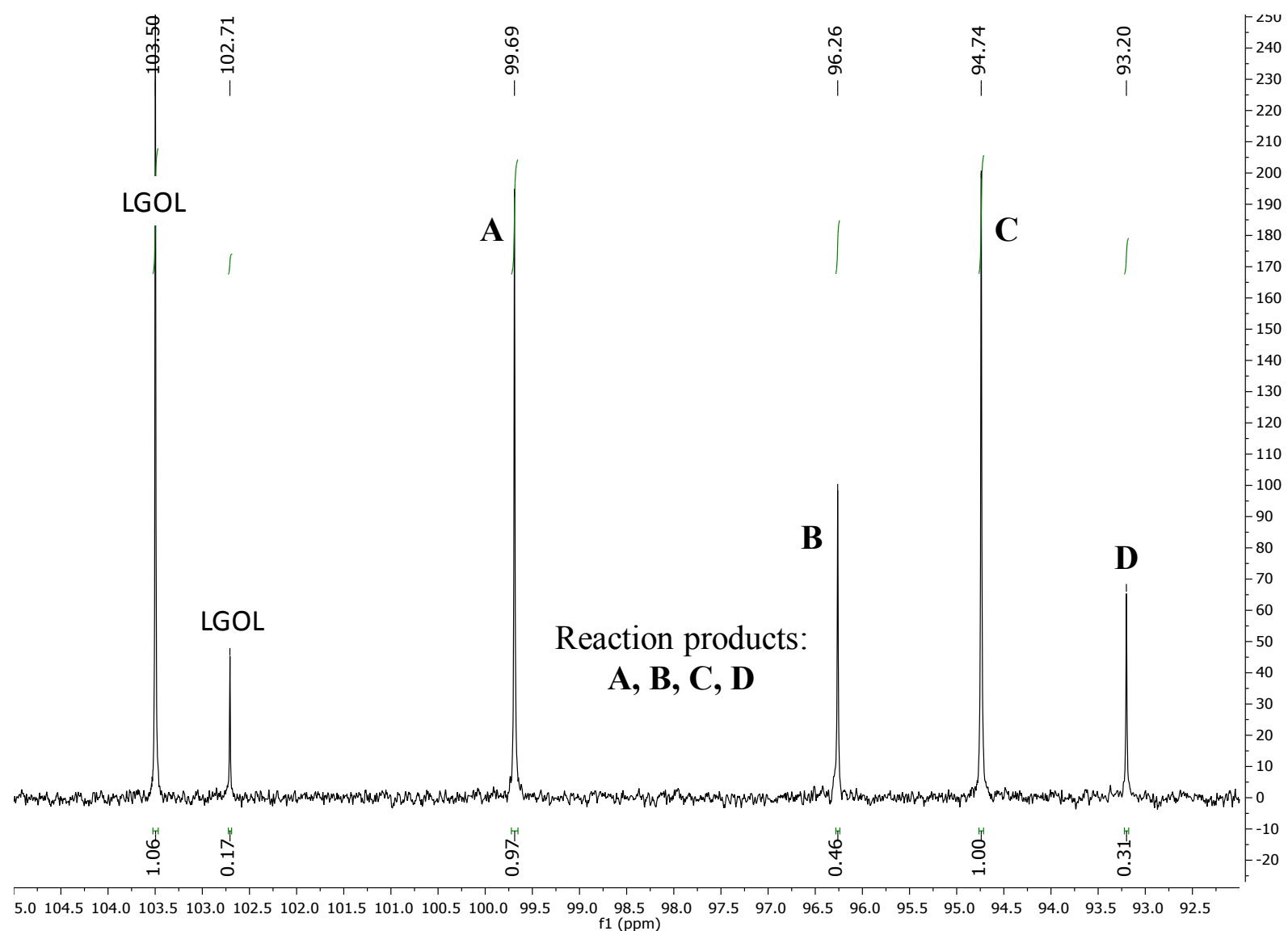

Figure S6. The anomeric carbon zone in ${ }^{13} \mathrm{C}$ NMR revealing the presence of remaining LGOL (erythro \& threo) and four triol diastereomers. " $\mathrm{A}$ " and " $\mathrm{D}$ " refer to the alpha and beta tautomer of DDG (we do not know which is alpha and which is beta). " $\mathrm{B}$ " and " $\mathrm{C}$ " refer to the alpha and beta tautomers of DDM (we do not know which is alpha and which is beta). Reported selectivities to DDM or DDG are calculated as the sum of the two tautomer peaks (e.g. $A+D$, or $B+C$ ). 


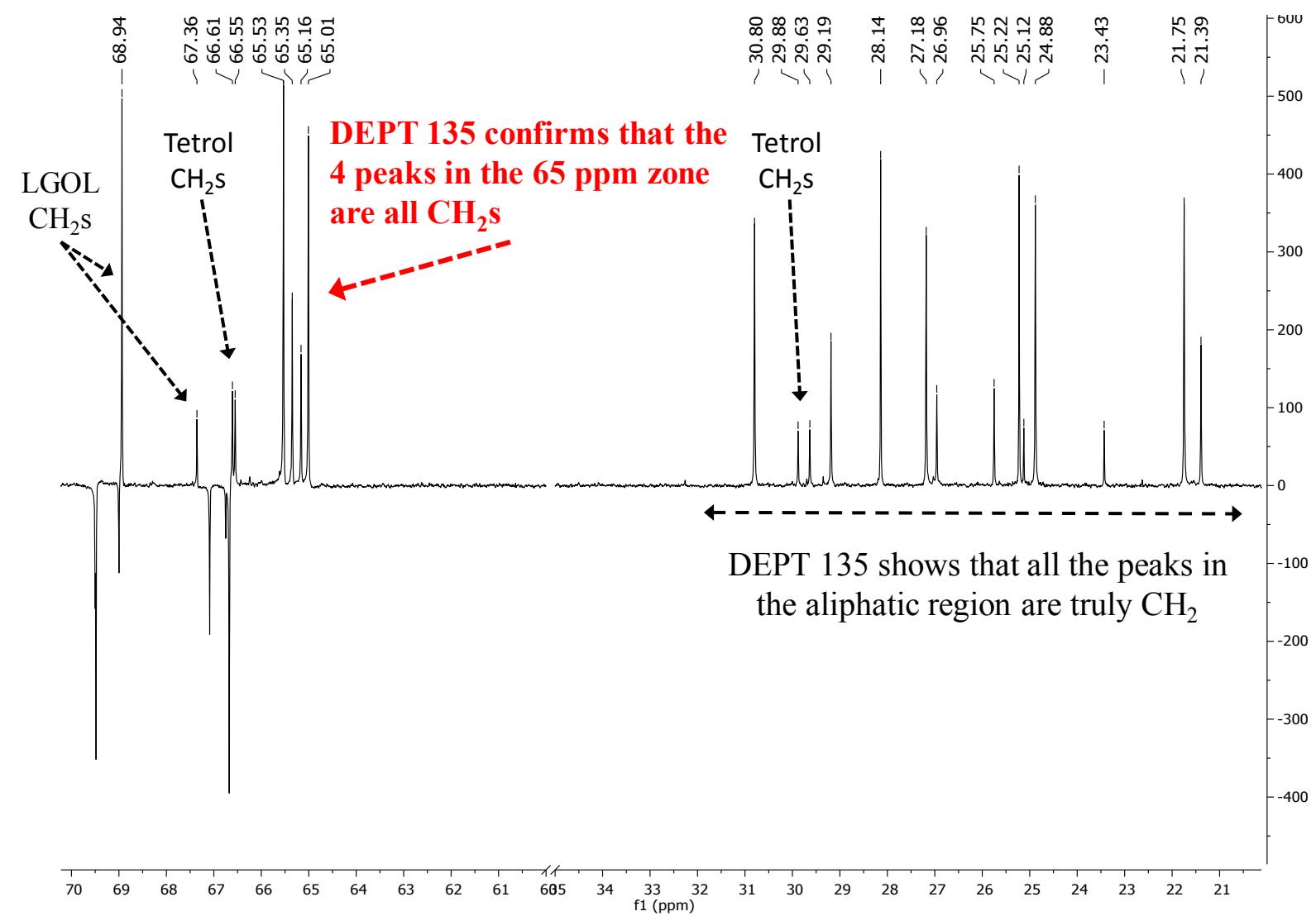

Figure S7. DEPT 135 analysis of a LGOL hydrolysis reaction mixture. Quantitative information was extracted from the $\mathrm{CH}_{2}$ zone around $64-70 \mathrm{ppm}$ where all relevant peaks are adequately separated, and where the relaxation is fastest [vis-à-vis the anomeric carbon $(\mathrm{CH})$ zone]. The clear presence of $\mathrm{CH}_{2}$ groups in this area (whether related to $L G O L,(S, S) /(S, R)$-tetrol or the four diastereomers) was confirmed with DEPT 135. 


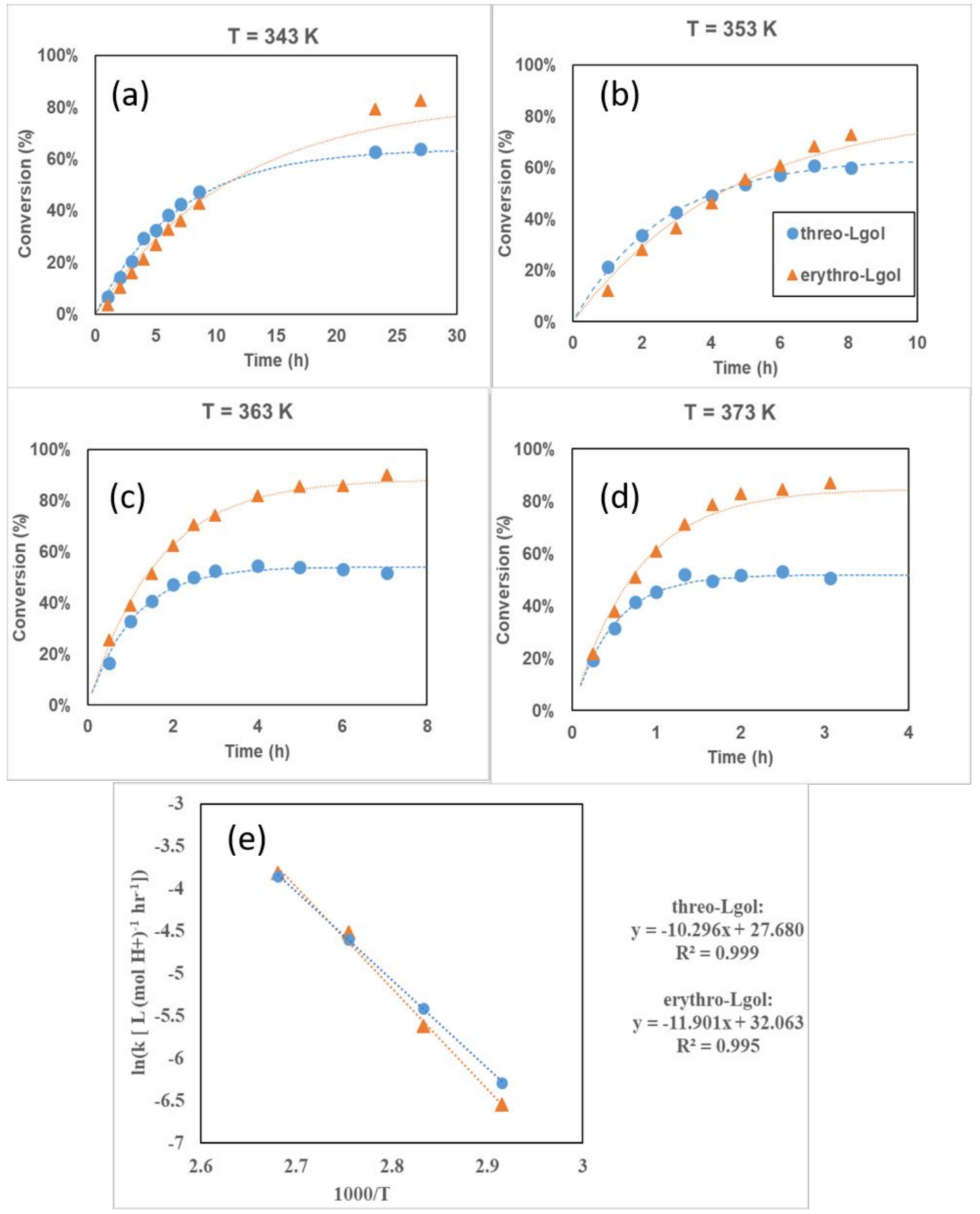

Figure S8. Experimental LGOL hydrolysis conversion versus time with $\mathrm{H}_{2} \mathrm{SO}_{4}$ catalyst in water at four temperatures: a) $343 \mathrm{~K}$, b) $353 \mathrm{~K}$, c) $363 \mathrm{~K}$, d) $373 \mathrm{~K}$ (dotted lines indicate fits to Equation 2), and e) Arrhenius plot based on these data (dotted lines indicate linear fits). The slopes in (e) are -10.296*1000 K for threo-Lgol and -11.901*1000 K for erythro-Lgol which represent $20.5 \mathrm{kcal} / \mathrm{mol}$ and $23.6 \mathrm{kcal} / \mathrm{mol}$ apparent activation energies, respectively. Conditions: $0.4 \mathrm{M} \mathrm{LGOL}$ in water $(\mathrm{TL} / \mathrm{EL}=1.6), 0.05 \mathrm{M} \mathrm{H}_{2} \mathrm{SO}_{4}$. 


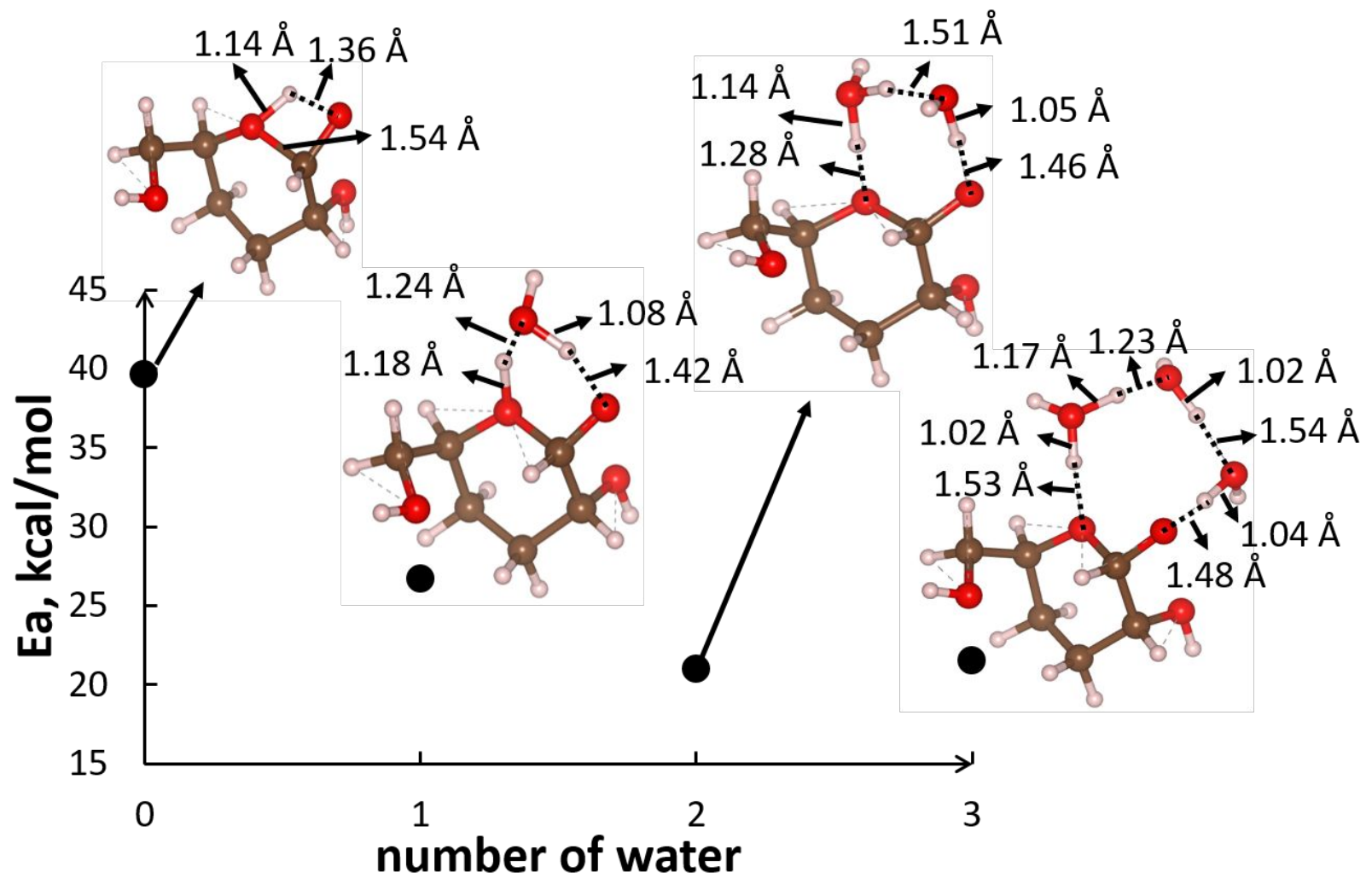

Figure S9. (a) Energy barrier of combined proton transfer and ring opening step for $\mathrm{G}_{1}$ to acyclic aldehyde form with different number of explicit water molecules using wb97xd level of theory. The brown, red, and white spheres represent $\mathrm{C}, \mathrm{O}$, and $\mathrm{H}$, respectively. 
(a) $\mathrm{G}_{1}{ }^{\mathrm{TS} 1}$

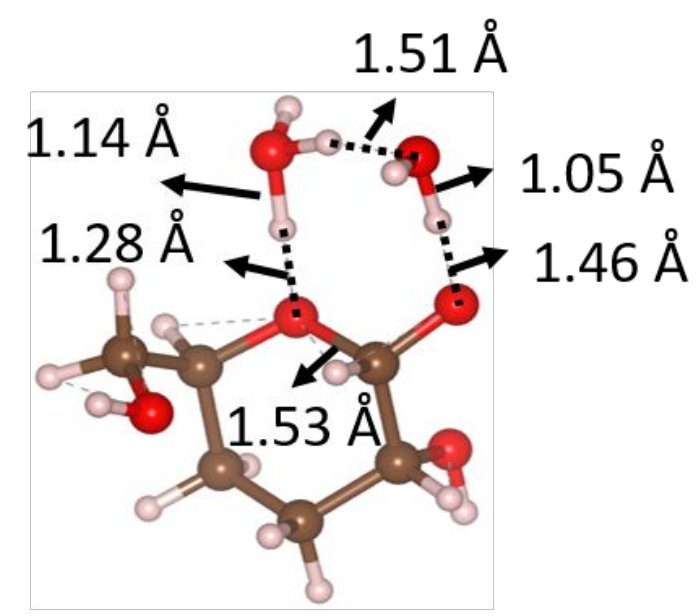

(c) $\mathrm{M}_{1}^{\mathrm{TS} 1}$

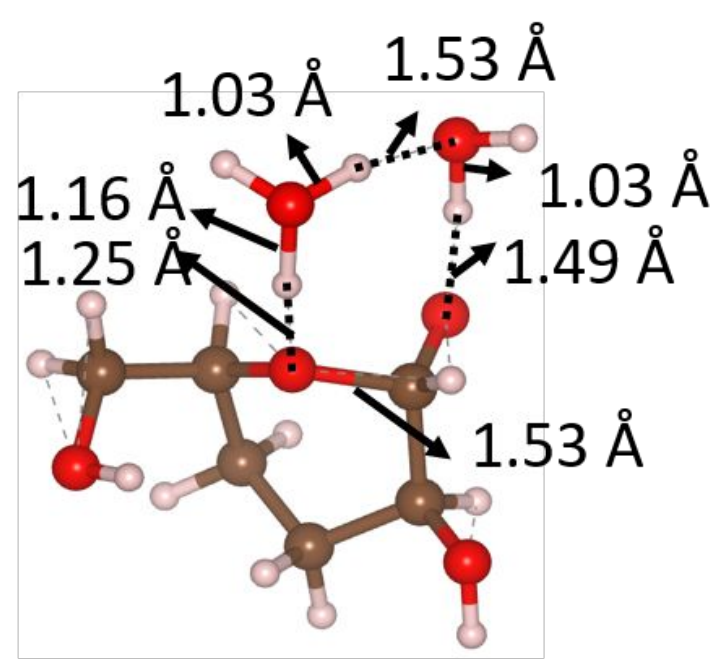

(b) $\mathrm{G}_{2}^{\mathrm{TS} 1}$

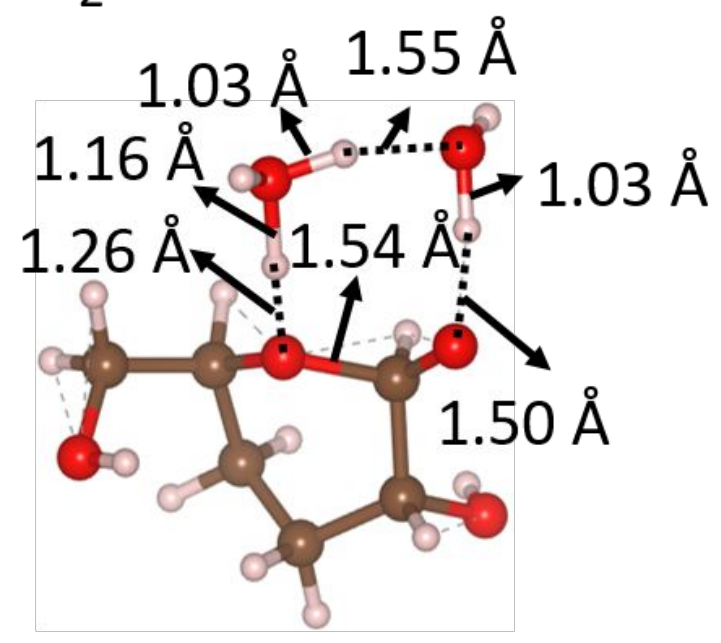

(d) $\mathrm{M}_{2}^{\mathrm{TS} 1}$

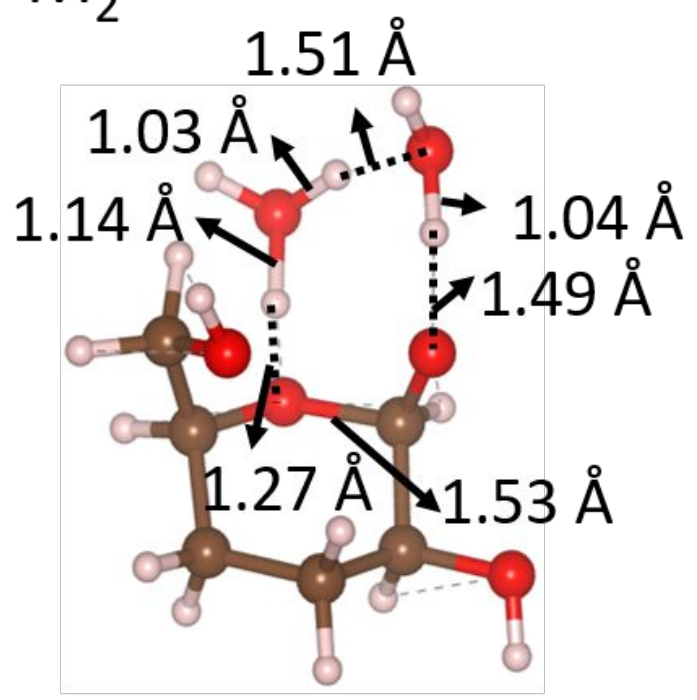

Figure S10. The optimized TS structures of $\mathrm{G}_{1}^{\mathrm{TS} 1}, \mathrm{G}_{2}{ }^{\mathrm{TS} 1}, \mathrm{M}_{1}^{\mathrm{TS} 1}$, and $\mathrm{M}_{2}^{\mathrm{TS} 1}$ shown in Figure 5. 


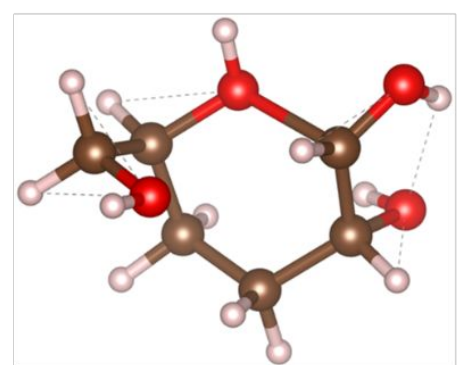

$G_{1} b^{11}$

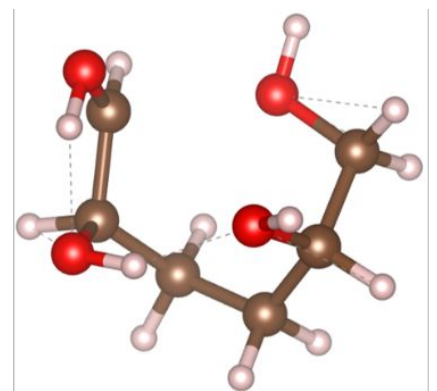

$G_{1} b^{12}$

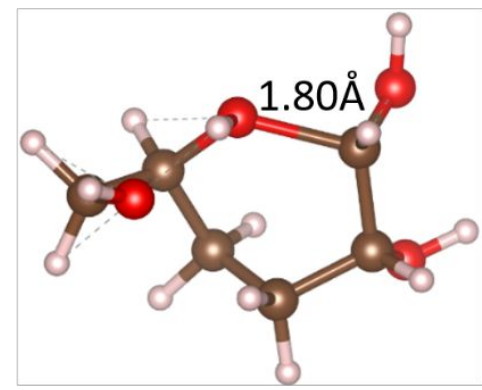

$\mathrm{G}_{1} \mathrm{~b}^{\mathrm{TS} 1}$
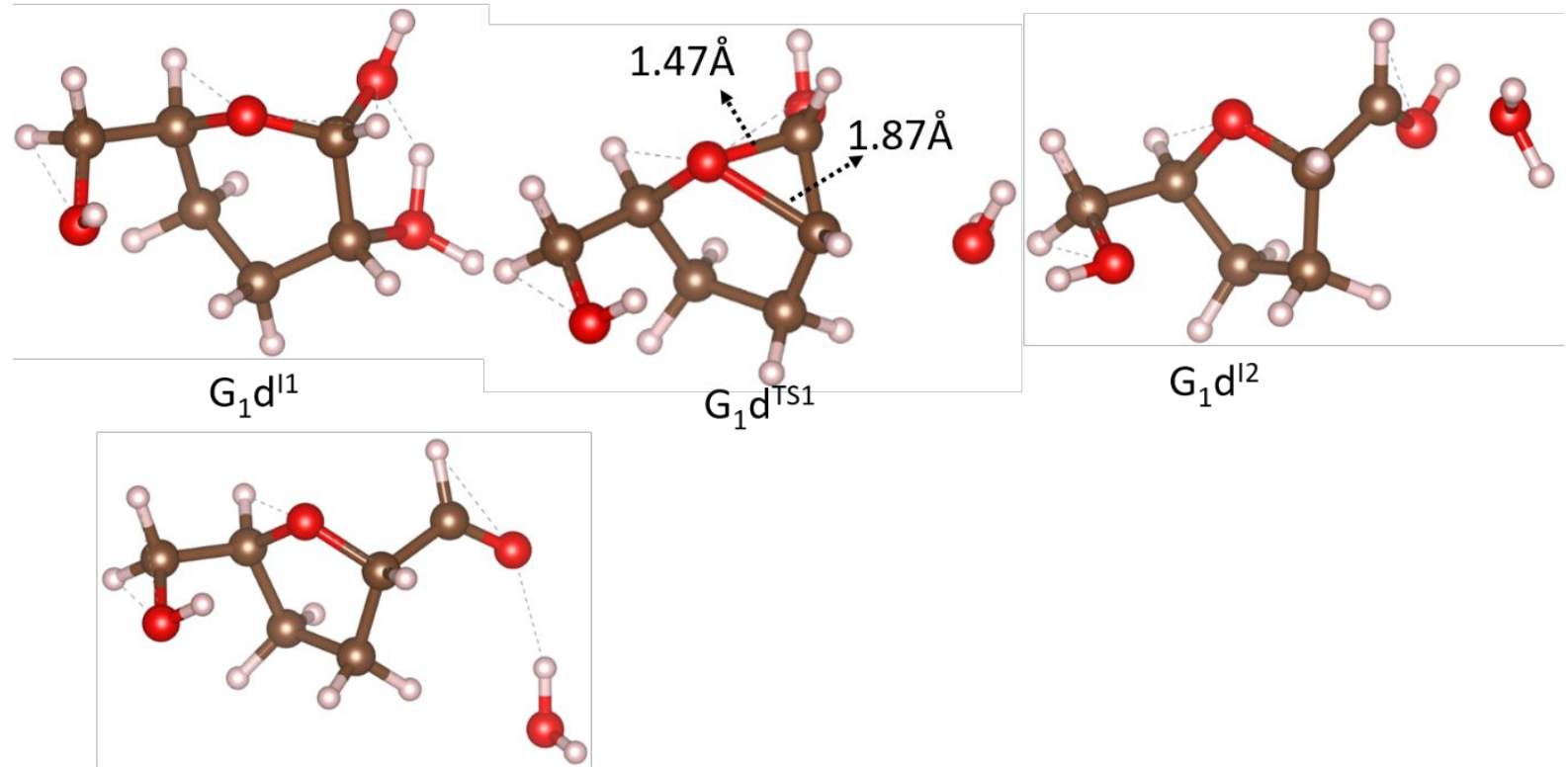

$$
\mathrm{G}_{1} \mathrm{~d}^{13}
$$

Figure S11. The optimized structures of reaction intermediates and TS of acid catalyzed cyclic-acyclic tautomerization of $\mathrm{G}_{1}$ from Figure 6 . 

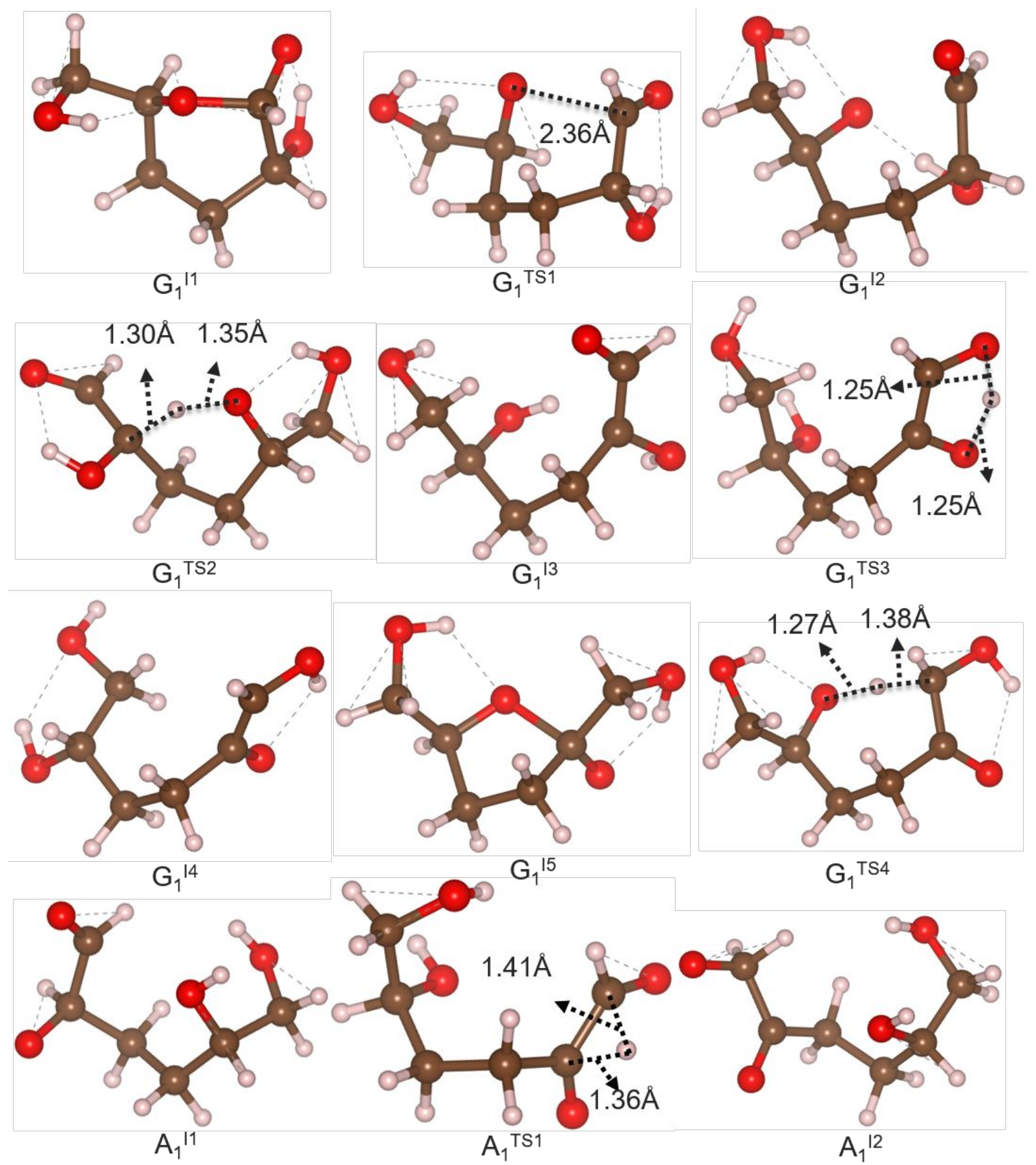

$\mathrm{G}_{1}^{\mathrm{TS} 4}$

Figure S12. The optimized structures of reaction intermediates and TS for base-catalyzed isomerization of $G_{1}$ and $A_{1}$ from Figure 7 . 


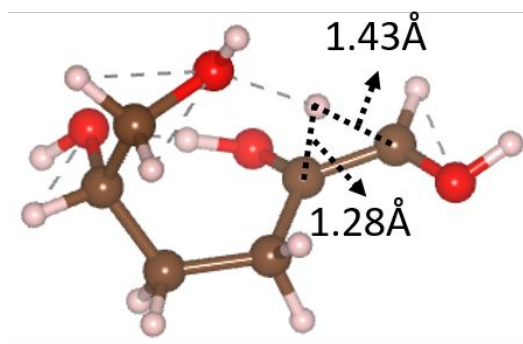

$\mathrm{A}_{1}{ }^{\mathrm{TS} 2}$

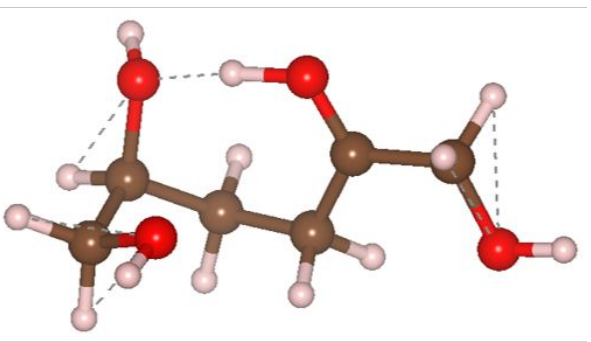

$\mathrm{A}_{1}^{13}$

Figure S13. The optimized structures of reaction intermediates and TS for acid catalyzed aldose-ketose isomerization between $\mathrm{G}_{1}$ and $\mathrm{F}_{1}$ from Figure 8. 


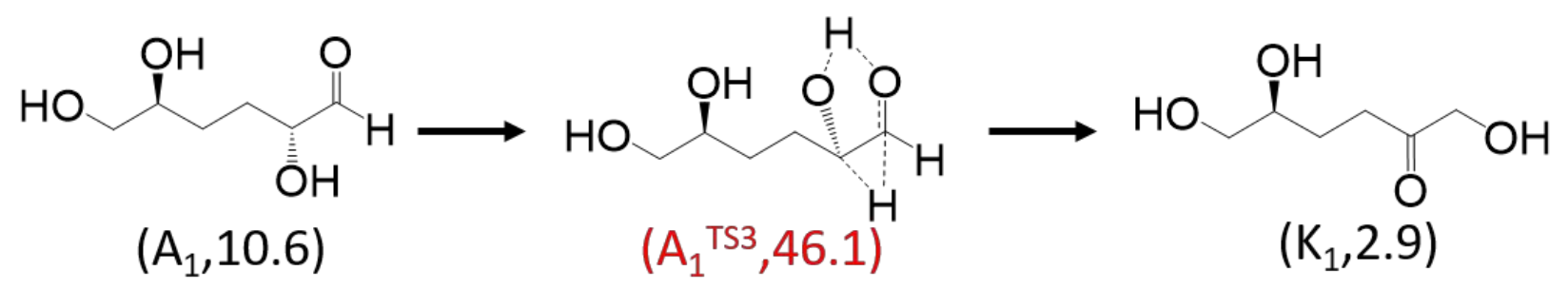

Figure S14. The reaction pathways and relative free energies $(\mathrm{kcal} / \mathrm{mol})$ of direct hydride shift of $\mathrm{A}_{1}$ to $\mathrm{K}_{1}$ at $298 \mathrm{~K}$. 


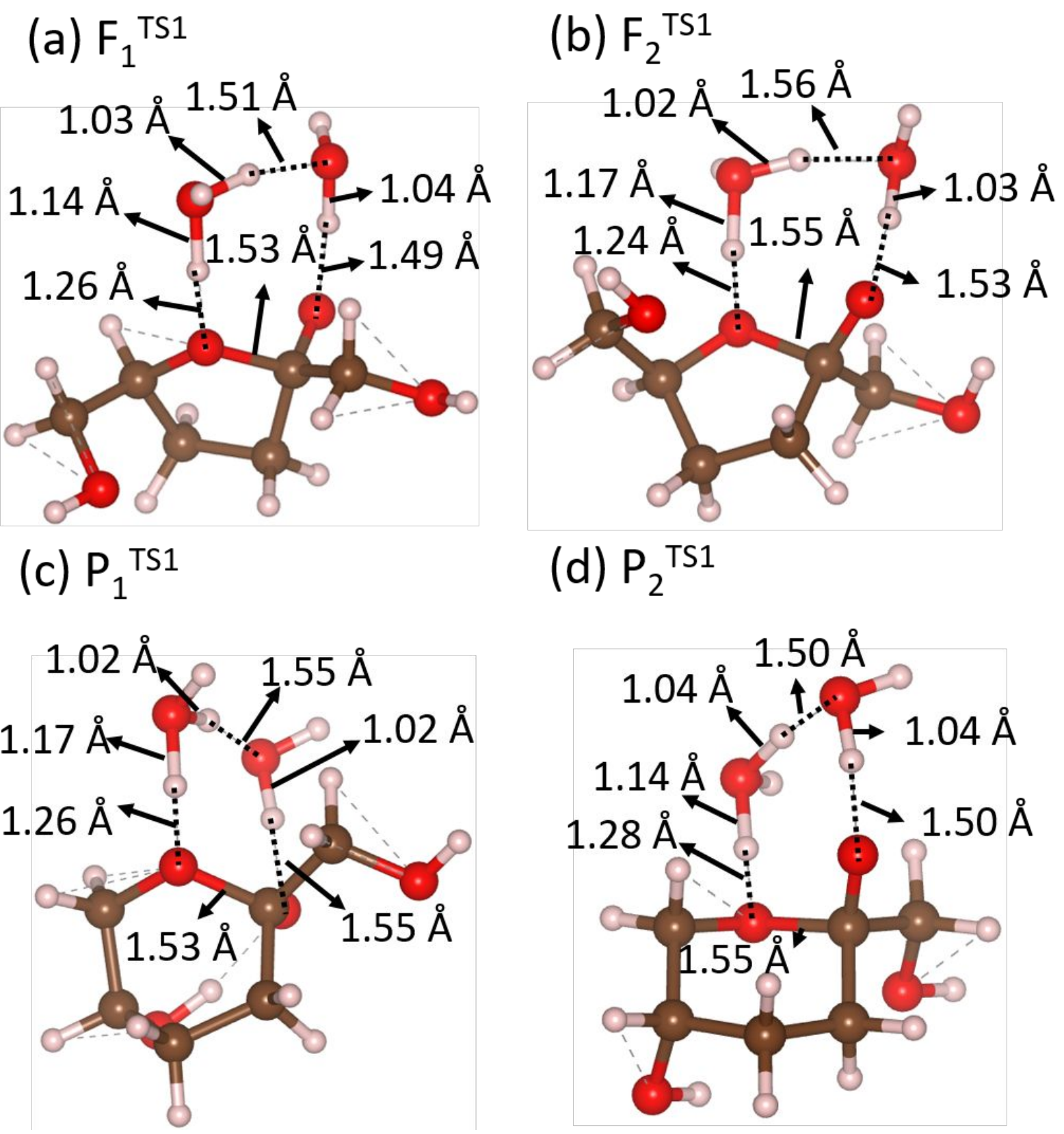

Figure S15. The optimized structures of TS structures of $F_{1}{ }^{\top S 1}, F_{2}{ }^{T S 1}, P_{1}{ }^{T S 1}$, and $P_{2}{ }^{T S 1}$ from Figure 9. 